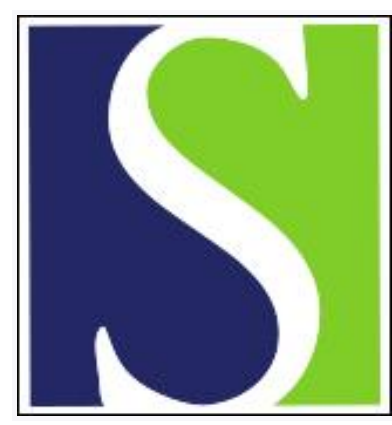

Scand J Work Environ Health 1999;25(6):605-609

https://doi.org/10.5271/sjweh.487

Issue date: Dec 1999

\title{
Knowledge jobs - how to manage without burnout?
}

by Kalimo R

The following article refers to this text: 2006;32(2):121-131

Key terms: information society; job demand

This article in PubMed: www.ncbi.nlm.nih.gov/pubmed/10884160

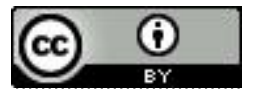




\title{
Knowledge jobs - how to manage without burnout?
}

\author{
by Raija Kalimo, $P h D^{\prime}$
}

\begin{abstract}
Kalimo R. Knowledge jobs - how to manage without burnout? Scand J Work Environ Health 1999;25(6, special issue):605-609.

The working world is progressing from the industrial era to the era of knowledge. The critical factor of success in work is shifting from machines to the human mind. All work that essentially uses and produces knowledge during and as a result of the work process can be defined as knowledge work. Knowledge jobs involve many healthpromoting features, but stress and burnout may be caused by the rapid increase in the knowledge-intensity of work, new job demands, and emerging new professional subcultures emphasizing excessive commitment to work. Very little empirical evidence is available on these developments. Much more research is needed to understand the essential features of knowledge work, the change in organizational cultures, and the values guiding this process from the point of view of human resources. Research is also needed to develop organizational strategies for the prevention of stress and burnout in knowledge jobs.
\end{abstract}

Key terms information society, job demands.

\section{Towards a knowledge-intensive worklife}

The working world is progressing from the industrial era to the era of knowledge. The critical factor of success in work is shifting from machines to the human mind. The productivity of knowledge and knowledge workers have been visioned as the most important factors of competition for most industries in the developed countries. What is knowledge is an old but still not unanimously answered question. It has been given at least the following meanings: information, cognition, knowing, awareness, experience, skill, competence, capability, knowhow, and wisdom. Consequently, knowledge work has not been precisely defined either. For a more coherent conceptual structure, knowledge has been characterized as a composite of information, skill, explanation, and understanding (1) (figure 1).
Roughly speaking, all work that essentially uses and produces knowledge during and as a result of the work process can be called knowledge work. It is worth noting that information, which has been considered a decisive factor in the discussion on the progress of the information society, is only one component of knowledge. Knowledge is more comprehensive than information (2), and, therefore, the scope of knowledge jobs is broader than that of so-called information work.

Compared with most traditional jobs, knowledge jobs are characterized by some new or enhanced demands and possibilities. Autonomy, learning opportunities, and the possibility for innovation are enhanced in knowledge jobs. The increased demand for personal commitment and ability to change, that is, the ability to adopt and apply new information, new methods, and new work procedures, is characteristic to knowledge jobs. It can be said
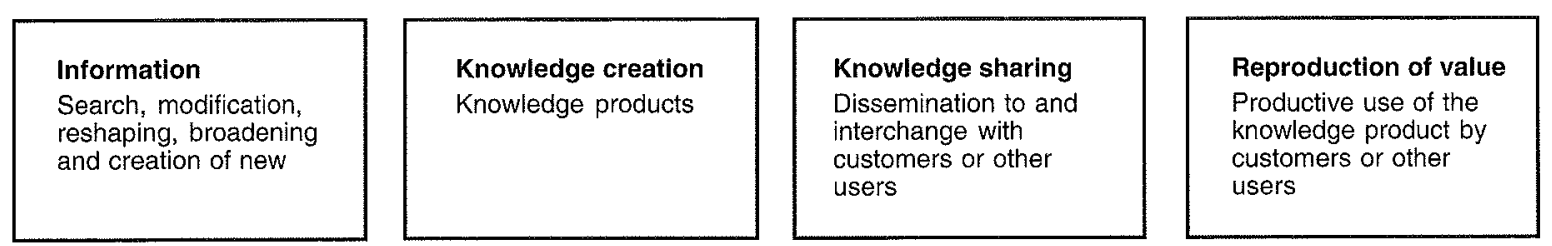

Figure 1. Core functions of knowledge jobs (1).

1 Finnish Institute of Occupational Health, Department of Psychology, Helsinki, Finland.

Reprint requests to: Professor Raija Kalimo, Finnish Institute of Occupational Health, Department of Psychology, Topeliuksenkatu 41 a A, FIN-00250 Helsinki, Finland. [E-mail: Raija.Kalimo@ occuphealth.fi] 
that knowledge intensity brings new challenges and developmental potential into work. The genuine features of knowledge work are therefore health promoting.

There is no doubt that knowledge workers will be in a strong position in tomorrow's society. According to some scenarios the knowledge industry may accelerate the polarization of people, knowledge workers being among the privileged with high prestige.

Knowledge work does not, however, mean self-evidently a rosy, impeccable future. As knowledge intensity increases in work, more and increasing concern about stress and burnout is brought into the discussion.

\section{What is burnout?}

According to the most broadly adopted theory, burnout develops as a consequence of prolonged stress at work. It is defined as a 3-dimensional syndrome, characterized by energy depletion (exhaustion), increased mental distance from one's job (cynicism), and reduced professional efficacy (3) (figure 2). Burnout was first recognized in the human service professions, and it was believed that emotionally demanding relationships with clients were the main cause of the problem. It has later become evident that burnout can develop in many kinds of work situations which exceed the resources of people to cope. This knowledge has led to the need for a partial revision of the basic theoretical assumptions about burnout and, consequently, also of the concepts used in the description of the syndrome.

Another theory recently brought into the discussion on the explanation of burnout is the equity theory or theory of reciprocity $(4,5)$. This theory postulates that burnout is caused by an imbalance between what a person invests in work and what he or she gains as material or symbolic returns. In essence, the theory suggests that workers conduct a cost-benefit analysis of their jobs. If the costs are chronically higher than the returns and if, especially, the situation is worse compared with that of other people, there is a risk of burnout.

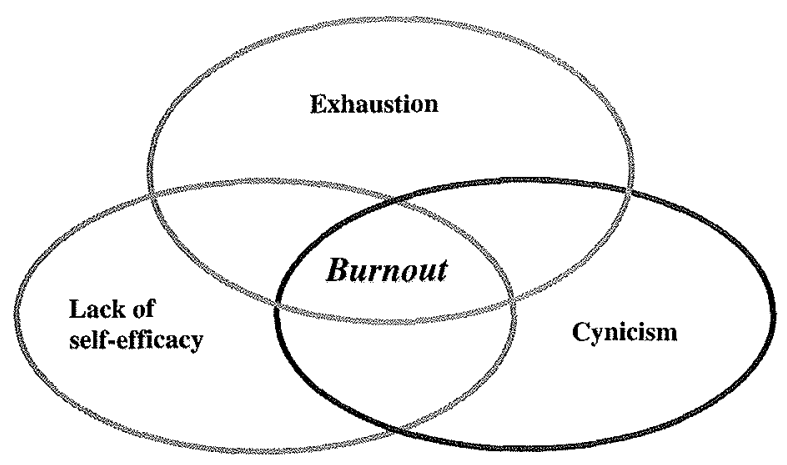

Figure 2. Burnout as a 3-dimensional syndrome.

\section{Job-related causes of burnout}

The factors contributing to the development of burnout can be multiple (5). Too heavy a work load (ie, excessive qualitative and quantitative demands) is one of the most important factors in situations provoking burnout. Knowledge jobs have several other typical stressors, a few of which were mentioned earlier. But it is not only the job (ie, the work itself) that causes burnout. Organizational factors always play a role too. A lack of possibilities to influence one's work and a lack of positive feedback are known causes of burnout as well. It can be summarized that work conditions that lead to the feeling of "nothing is enough, nothing helps" are crucial in the development of burnout. Poor interpersonal relations and other additional factors that consume energy may aggravate the situation. Individual factors also play some role.

Empirical research on burnout has been the most frequent in the areas of health care and other human services, but it is increasing also in other occupations. In the study of burnout in knowledge jobs, a shift of emphasis has to be made from the emotional load related to interpersonal contacts to the more cognitive load typical of information work. The studies currently available point out that current organizational and individual resources for coping with the information load in knowledge jobs is severely threatened.

The increasingly heavy communication of information has been found to cause high information overload in offices (6). Roughly 1 out of 2 managers reported being often or very often unable to handle the volumes of information they received. On the other hand, information was thought to be underutilized by 2 out of 3 of the managers. In another study (7) information overload was the main stressor of computer professionals, and it was related to a lowered sense of professional competence. Computer professionals also suffered more frequently from burnout than a control group of other professionals did. A great majority of the computer professionals felt that it was impossible to cope with the bulk of new information, whereas these problems were less frequent in the comparison groups (table 1).

\section{Attention to contextual factors}

The possible sources of burnout in knowledge jobs are much broader than those related to information (figure 3). Knowledge work is contextually dependent, like any other work. Knowledge work is mostly done in organizations, but it will increasingly be done in different kinds of networks in the future, not in organizations in the traditional sense. Nevertheless, these systems have 
common, shared features that differentiate them from other organizations. It is said that knowledge organizations are flatter, have less formal structures, and give more independence to their members (8).

Although different knowledge organizations may share some common features in the same way as hospitals or schools do, each particular knowledge organization or network may develop its own ways of being and doing - in other words, its own culture. Therefore, for instance, management, the distribution of labor, and communication may differ in knowledge organization A compared with $B, C$, and $D$. The situation is changing so rapidly that one may ask how much we really know about what is happening? More research is needed on these developments.

\section{Info-holic culture?}

It is to be noted also that professions that share certain unique homogeneous characteristics that differentiate them clearly from other professions tend to develop their own professional norms and subcultures. There are already signs that a somewhat particular knowledge worker culture is developing. In other words, a person has to be within the reach of new information at all times. The counting of workhours and sticking to a rigid regular daily or weekly work schedule does not, in turn, fit this emerging culture. Overindulgence in the Internet has been noted (9). A professional subculture may have health-promoting trends, but also the opposite is possible. The same can be said about the broader social structures and general culture in society, both of which shape basic values and norms. Increased awareness is needed to recognize ongoing changes in the working world from the viewpoint of human limits and resources.

\section{Risk of burnout in association with social megatrends}

Research on burnout has been mostly limited to factors related to job characteristics and other factors based on the internal dynamics of work organizations. Broader social contexts have been largely ignored. The social changes experienced in the 1990 s are, however, gradually increasing the awareness of the importance of these factors in burnout as well.

One of the prominent recent trends in the working world has been an increase in workhours. In the Finnish population burnout was more common among those working over 55 hours a week. The greatest amount of extra hours was worked by people with an academic education, and the majority of knowledge workers currently belong to this group. Among them, 1 person out of $2(53 \%)$ worked 40 to 55 hours a week in their main job, and $14 \%$ worked over 55 hours. It is important from the viewpoint of burnout risk that a large proportion of those who worked overtime did not get any compensation for their extra hours. More than half of the academically educated people worked overtime without any compensation, while $73 \%$ of the others got either pay or free time in return (10).

This situation increases the risk of burnout according to the reciprocity theory. In the preceding sample, the academically educated people invested extra hours in their work, and they invested their own time, which is normally paid back, but in this case was not. A strong correlation was found between various kinds of imbalance between personal investments and the rewards received and burnout in the Finnish population (11).

An increase in workhours seems to be a general trend worldwide. Similar findings have been reported in the European Union, the United States, and Japan, to mention a few. It has been calculated that Europeans have a 20-hour weekly deficit in their time budgets (12). This development has increased stress-related problems. Already for decades it has been known that extensive

Table 1. Information overload among computer professionals and others (7).

\begin{tabular}{|c|c|c|c|}
\hline & \multicolumn{3}{|c|}{ Often or continuously (\%) } \\
\hline & $\begin{array}{l}\text { Computer } \\
\text { professional }\end{array}$ & $\begin{array}{l}\text { Computer } \\
\text { semi- } \\
\text { professional }\end{array}$ & Others \\
\hline $\begin{array}{l}\text { Feels that the bulk of relevant } \\
\text { information is always greater }\end{array}$ & & & \\
\hline than one can cope with & 70 & 56 & 50 \\
\hline $\begin{array}{l}\text { Selecting the relevant information } \\
\text { from the information flow is tedious } \\
\text { Keeping up with new information }\end{array}$ & 44 & 33 & 35 \\
\hline is a strain & 41 & 32 & 26 \\
\hline $\begin{array}{l}\text { Working with a continuous flow } \\
\text { of information is a strain }\end{array}$ & 39 & 27 & 32 \\
\hline
\end{tabular}

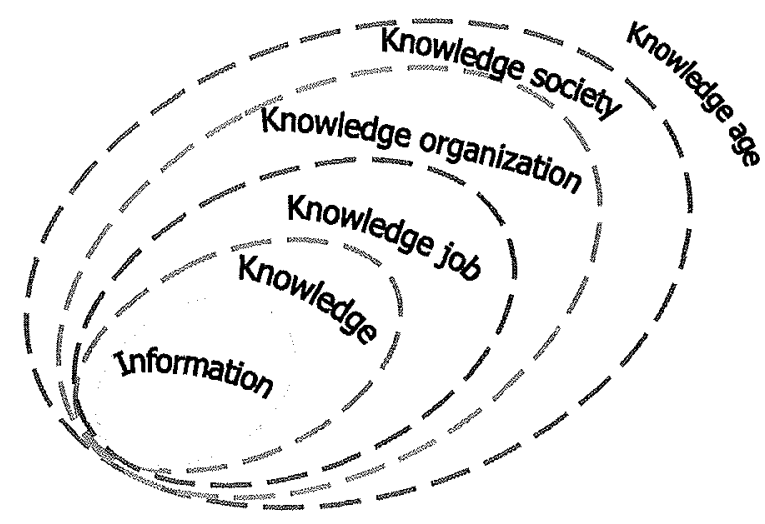

Figure 3. Knowledge jobs in a social context. 
overwork increases health disorders, and the official workhours have become controlled by legislation. Nevertheless this trend towards longer workdays continues. This is a paradox also because, at the same time, the number of unemployed people remains high. A editorial of the Work and Stress Journal (13) characterized this situation as an indication of adopting a workaholic culture. Michie \& Cockroft (14), in turn, characterized the same situation with the startling title of their paper "Overwork Can Kill".

It is paradoxical that simultaneously as the workday is becoming longer, people experience more and more haste and time pressure at work. It seems that the more one works the more work is left undone. Time pressure was found to be strongly related to burnout among the managers of an industrial corporation. The relation of stressors, including time pressure, to burnout were strengthened in software development teams if the cognitive requirements and learning requirements were high (15).

There are also other macrolevel trends that have not yet been investigated sufficiently in burnout research. The labor force has been reduced strongly as a response to economic setbacks in the early 1990s, namely, during the period of increasing demands for new competencies and a marked increase in productivity. The risk of burnout in Finland was about twice as high in organizations which had implemented personnel reductions of various kinds as an economic measure (10). Those who suffered from burnout had more often sleep disorders, used more health services, and were more often considering premature retirement than the others.

\section{Prevention of burnout - towards comprehensible, managable and meaningful work}

Workers in knowledge jobs can be particularly harmed by the consequences of burnout. Innovativeness, flexibility, learning, and memory are not at their best in burntout persons - nor are social skills or readiness for social interaction, which will be increasingly important in the knowledge jobs of the future.

Burnout can be prevented by organizational means and people-oriented approaches. One of the basic measures is to adjust work load through prioritization in decision making and through the reorganization of work. An increase of influence, support for professional development, less bureaucracy, and increased feedback are among the means to prevent burnout. In knowledge jobs loaded by information, specific strategies must be developed to control useless information and its hampering effect on knowledge processing. On the other hand, measures are needed to cope with information, which is inevitably increasing.

It is important to realize that real knowledge that deepens understanding does not increase automatically with the proliferation of information. The Finnish minister of education recently pointed out that no more essential new knowledge is produced nowadays than in the 14 th century or even a thousand years earlier. This need not be taken as an exact statement, but the core of the message is clear. Endless possibilities for copying, multiplication, and the transferring of present information, and even knowledge, with the augmenting technologies should not be allowed to distort the vision of the actual situation.

Value judgments are made when the kind of information and knowledge that is needed and the additional value of new applications are defined. Such judgments are being made more or less openly in all arenas of society. Work organizations should draw up their own conscious value-based strategies for the intake and production of information and knowledge.

Work organizations must also participate in changing values that overemphasize short-sighted economic gains through the ignorance of people. In a healthy organizational culture burnout does not become a problem. Therefore, ideally, no specific actions are needed for the prevention of burnout; it is avoided if careful attention is paid to the resources of people as a part of normal daily work. Continuous learning is characteristic of these kinds of organizations.

A question in itself is the solving of the availability of necessary safety nets and support systems for the increasing number of people who work on their own outside traditional organizations. As yet, no solutions have been developed for this problem, and even the needs are still mostly unknown.

The people themselves may also be capable agents in the mastery of their work situations. Problem-focused coping strategies to initiate changes in work conditions should be developed when needed. Attitudes towards work may need revision in work cultures based on rapidly changing knowledge production and usage. The growing need for self-help in the maintenance of wellbeing should, however, not prevent one from recognizing that severely burntout persons need health care and rehabilitation.

\section{Many research needs in prevention}

Information on the results of efforts aiming at the prevention and treatment of burnout on an organizational basis is scarce. Individual success stories have been reported (16), and these stories may counterbalance 
other examples showing that burnout tends to be persistent and become chronic when nothing is done. The process of burnout, which usually takes several years, should be studied much more in order to offer a basis for timely prevention. Preventive strategies and the process of recovery from burnout should be taken as targets of forthcoming research in this field. Further research is needed also on economic factors in the causation of burnout and in its consequences.

\section{References}

1. Wickström S, Normann R. Knowledge and value: a new perspective on corporate transformation. London: Routledge, 1994.

2. Chmiel N. Jobs, technology and people. London: Routledge, 1998.

3. Schaufeli W, Enzmann D. The burnout companion to study \& practice - a critical analysis. London: Taylor \& Francis, 1998.

4. Adams JS. Inequity in social exchange. Adv Exp Soc Psychol 1965;2:267-99.

5. Buunk BP, Schaufeli WB. Professional burnout: a perspective from social comparison theory. In: Schaufeli WB, Maslach C, Marek T, editors. Professional burnout: recent developments in theory and research. Washington (DC): Taylor \& Francis, 1993:53-69.

6. Reuters Business Information. Dying for information: an investigation into the effects of information overload in the UK and worldwide. London: Reuters Limited, 1996.
7. Toppinen S, Kalimo R. Henkinen väsymys, kyynisyys ja ammatillinen pätevyyden tunne: ytöuupumusta ennsutavat tekijät tietotekniikan ammattilaisilla ja muilla [Exhaustion, cynicism and professional self-efficacy: factors that predict burnout of computer professionals and others]. Työ ja Ihminen 1995;4:235-54. English abstract.

8. Pankakoski M. Knowledge sharing and value reproduction: the work flow as a case example. Espoo (Finland): Helsinki University of Technology, Department of Industrial Management, 1998. Work and organizational psychology, report no 6

9. Brenner V. Psychology of computer use, XLVII: parameters of Internet use, abuse and addiction: the 90 days of the Internet usage Survey. Psychol Rep 1997;1:879—82.

10. Kalimo R, Toppinen S. Työuupumus Suomen työikäisellä väestöllä [Prevalence of burnout in the Finnish working population]. Helsinki: Finnish Institute of Occupational Health, 1997.

11. Kalimo R, Taris T. Burnout - an increasing problem of modern work life. Paper presented in the XI World Congress of Psychiatry, Hamburg 6-11 August, 1999.

12. High-level Expert Group. Building the European information society for us all: final policy report of the high-level expert group on information society. Brussels: European Commission, 1997.

13. Working hours and health [editorial]. Work Stress 1996;10:1-4.

14. Michie S, Cockroft A. Overwork can kill. BMJ 1996;312:921-2.

15. Sonnentag S, Brodbeck FC, Heinbokel T, Stolte W. Stressorburnout relationship in software development teams. J Occup Organ Psychol 1994;67:327-41.

16. Bernier D. A study of coping: successful recovery from severe burnout and other reactions to severe work-related stress. Work Stress 1998;12:50-65. 